\title{
BASIC PREMISES OF MULTIDIMENSIONAL ATTITUDE CHANGE THEORY: AN EXPERIMENTAL ANALYSIS
}

\author{
JOSEPH WOELFEL \\ SUNY-Albany
}

JAMES GILLHAM
SUNY College-Buffalo

\author{
MICHAEL J. CODY \\ Texas Technological University \\ RICHARD A. HOLMES \\ SUNY-Albany
}

\begin{abstract}
Multidimensional attitude change models propose that (1) stimuli defining the domain of attitudes may consist of a multidimensional rather than unidimensional pattern; (2) stimuli associated with each other in the persuasion process will converge with each other in the multidimensional attitude domain. These two propositions receive clear support from three of the hypotheses tested in four-panel cohort data, which analyses show to be multidimensional. The sources of a persuasive message converge on the position they advocate. Multiple sources converge on each other. The findings provided partial support for two other hypotheses on the convergence of self-concept with advocated position and with sources of a persuasive message. A final, somewhat tangential hypothesis also receives clear support: existential associations of concepts are more effective than hortatory associations. These results support further development of multidimensional attitude change models.
\end{abstract}

Among attitude researchers, the superiority of multidimensional approaches for describing complex cognitive domains has won wide acceptance. The work of Osgood et al. (1957) is especially well known in the communications field, where several key variables are routinely measured by multidimensional methods (see works on credibility by Berlo et al., 1969; McCroskey, 1966; Wakshlag \& Edison, 1975).

Only recently, however, have experimental inquiries into attitude change begun moving beyond the unidimensional approaches typified by Osgood and Tannenbaum (1955) and Hovland et al. (1957).

\footnotetext{
Joseph Woelfel (Ph.D., University of Wisconsin, 1968) is associate professor of rhetoric and communication, SUNYAlbany, N.Y. 12222. Michael J. Cody (Ph.D., Michigan State University, 1978) is visiting assistant professor of communication at Texas Technological University, Lubbock, Texas 79409. James Gillham (Ph.D., University of Illinois, 1972) is assistant professor of criminal justice at SUNY-Buffalo, Buffalo. N.Y. 14222. Richard A. Holmes is director of computer operations at Capital Districts Humanities Program, SUNY-Albany, N.Y. 12222.
}

In a typical unidimensional attitude study, all of the action is assumed to be played out on a single unidimensional continuum or line, on which are projected the receiver's position, the perceived position of the source, the position advocated, and the resulting position of the receiver.

Multidimensional studies do not make this assumption, but rather assume in any instance that these points-that is, the receiver's position, the perceived position of the source, the position advocated, and the resulting position of the receivermay take any orientation whatsoever with regard to each other.

The possible outcomes of various different arrays in such multidimensional spaces have been covered in more detail elsewhere (Woelfel \& Saltiel, 1979), and the interested reader is referred to this source for a more elaborate discussion. Figure 1, however, illustrates the relationship between unidimensional and multidimensional representations in one of the simplest cases. This figure shows the locations of two sources of messages (A and B), the positions of 
FIGURE 1

Projections of a Two-Dimensional Attitude Domain onto a Unidimensional Category Scale

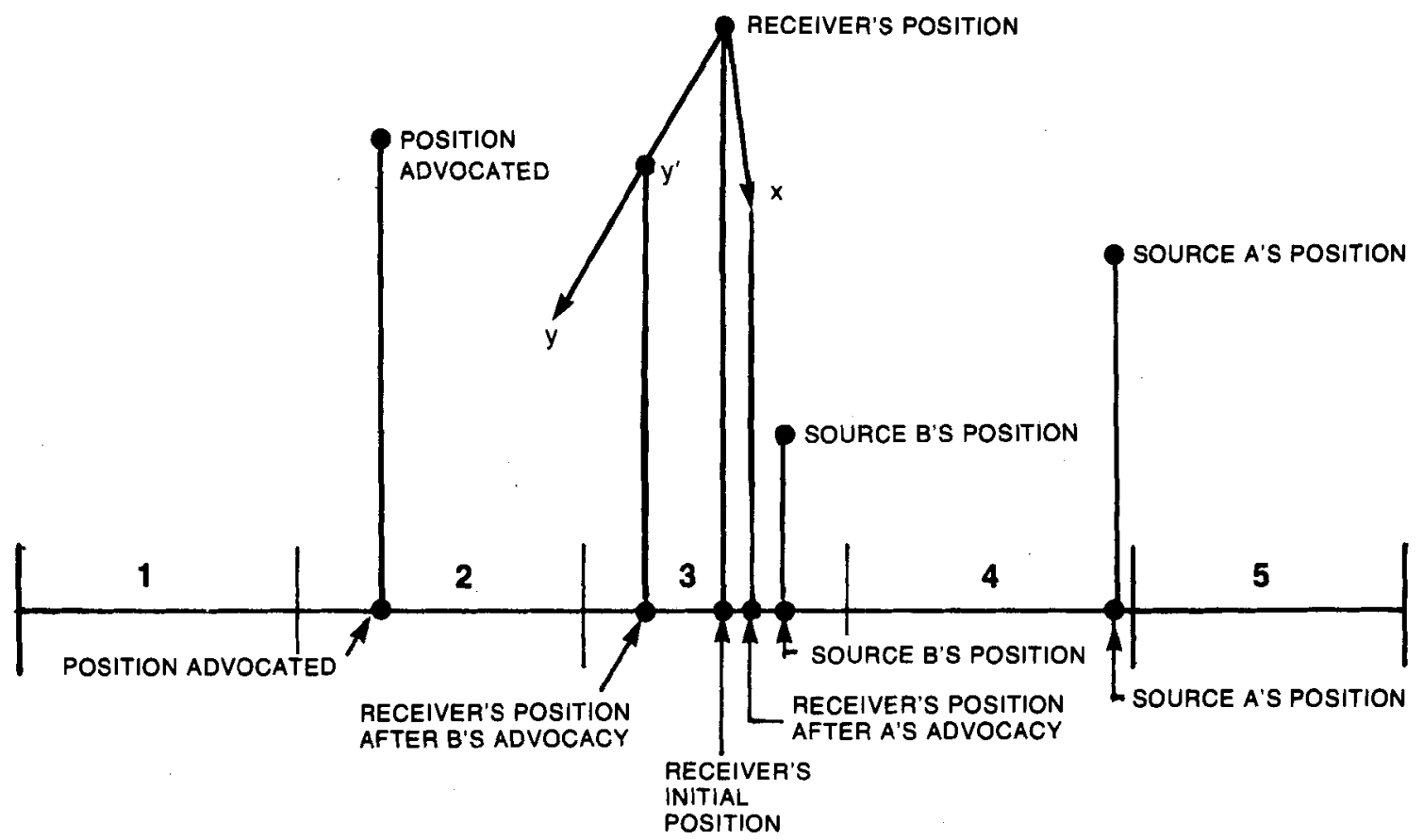

the receiver of those messages, and the location of the position advocated in those messages. For simplicity, these are shown arrayed on the plane (a two-dimensional space), although their actual locations and the dimensionality of the space within which they are arrayed is an empirical question which must be answered by measurements.

The line segment near the bottom of the illustration represents a five-interval Likert-type or semantic differential-type scale, typical of conventional practice, projected on the plane. (The orientation of a unidimensional scale in a multidimensional space is also an empirical matter, and procedures for projecting unidimensional scales into multidimensional spaces may be found in Gillham and Woelfel (1977) and Woelfel and Danes (1979). The four labeled points represent the projections of this twodimensional array onto the one-dimensional line segment. These are the values that would have been obtained had the positions of these four objects been measured with a five-interval Likert-type.

Note that certain distortions result from this projection: on the unidimensional scale, for example, the receiver's initial position and the position of source B seem nearly the same, yet, in the twodimensional representation, we see that they are actually quite distant from each other. The exact character of the distortions due to projecting a multidimensional continuum onto a unidimensional scale is a function of the geometry of the array of points and the orientation of the unidimensional scale within the array. Nonetheless, some distortion is inevitable and under all but the rarest and most simple of circumstances will be quite substantial.

Just as they distort the structure of static representations, unidimensional scales can provide highly distorted representations of processes in the attitude domain. Processes in the attitude domain (such as a change of attitude) are represented by motions of the points through the space. In a multidimensional space, any object is free to move in as many independent directions as there are dimensions in the space (in fact, this is the original meaning of the term "degrees of freedom," since each 
dimension adds one degree of freedom to the range of possible motions), while on the unidimensional scale, points can only move back or forth on the line. Figure 1 provides several examples of the way unidimensional scales provide distorted measures of multidimensional processes.

For the purposes of the example, we assume that the receiver responds to an advocacy message by interpreting an appropriate position midway between that position explicitly advocated and the position the receiver believes the source to occupy. In Figure 1, in this case, a message from source A advocating the receiver adopt a particular position would move the receiver's own position toward the midpoint of the line segment between receiver's perceptions of the advocated position and source $A$ 's position. If we assume that source $A$ is totally credible, then the receiver's position should shift to the point marked " $x$ " in Figure 1.

Notice, however, that the projection of this new position of the receiver on the unidimensional scale is further than the receiver's initial position from the advocated position. This, then, appears to be an example of the often-observed "boomerang effect," since it is a net motion away from the position advocated.

Based on the same initial assumption, B's advocacy should result in a shift of the receiver's position toward the midpoint, marked " $y$ " in Figure 1, of the line segment connecting source B's position with the position advocated. If we arbitrarily assume source B to be only half as credible as source $A$, then the receiver's position will shift only half the distance advocated to $y^{\prime}$ instead of $y$. This change, when projected onto the unidimensional scale, appears to be in the direction advocated and, moreover, appears to be about twice the magnitude of the change induced by source $A$, even though, in the two-dimensional representation, the magnitude of the change induced by source A was actually greater.

These distortions resulting from the unidimensional constraints of conventional measurement practices are compounded by the categorical nature of the scales typically employed in such studies. Both of the changes described above, for example, would clearly go entirely unnoticed in the absence of very substantial samples, since the projections of the changes onto the unidimensional scale in Figure 1 are not large enough for either source A or B to extend over the category boundary of the fiveinterval scale. Had the same changes occurred near a category boundary (i.e., where two and three or three and four meet on the scale), the likelihood that the changes would be detected by the scaling instrument would increase considerably. This means that the unidimensional category scale typical of conventional attitude change studies is not only imprecise but also differentially sensitive along its length. This in turn means that linear changes will be mapped as nonlinear motions and, combined with the effects of multidimensional processes projected onto the unidimensional scale, may even be mapped nonmonotonically. On formal, geometric grounds alone, therefore, it is clear that unidimensional category scales will misrepresent attitude change processes very severely in all but the rarest of empirical circumstances.

Effects identical to those predicted by the preceding analysis are fairly commonly observed in unidimensional attitude change studies. Most previous studies show a roughly linear relation between the magnitude of change advocated and change observed (Aronson et al., 1963; Bergin, 1962; Bochner \& Insko, 1966; Fisher \& Lubin, 1958; Freedman, 1964; Goldberg, 1954; Helson et al., 1958; Hovland \& Pritzker, 1957; Rosenbaum \& Franc, 1960; Tuddenham, 1958; Zimbardo, 1960). Sometimes, however, nonlinear and even nonmonotone ("boomerang') effects have been noted, particularly with messages sent by low or medium credibility sources (Ableson \& Miller, 1967; Aronson et al., 1963; Bergin, 1962; Berscheid, 1966; Bochner \& Insko, 1966; Freedman, 1964; Insko et al., 1966; Kelley \& Volkhard, 1952; Mann, 1965). In longitudinal studies, delayed changes (usually reversions toward the original position) have also been noted (Hovland et al., 1953; Hovland et al., 1949; McGuire, 1969).

Unidimensional studies not only produce effects that frequently resemble distortions predicted by the geometry of multidimensional representations, but also leave unexamined a great number of additional relationships which might change during the advo- 
cacy process, such as the relationship between the self and the sources, the sources and each other, the sources and the position advocated, and so on. All these relationships are arrayed automatically in the multidimensional representation. For simplicity, changes in the positions of the sources and changes in the perceived location of the position advocated were not represented in Figure 1. But, in the absence of prior data, no point in the multidimensional continuum ought to be assumed unaffected by advocacy. Since the multidimensional procedure represents all these possible associations and changes of associations simultaneously, it is not necessary to assume any of them to be invariant under the attitude change transformation, although most unidimensional studies do make such assumptions routinely.

The recent development of convenient multidimensional scaling systems (see Shepard, 1972) has brought a number of multidimensional analyses of cognitive and cultural processes (Serota et al., 1977; Cody, 1976). But the assumptions underlying such analyses still lack a firm base of experimental evidence. Top priority, therefore, should go to careful, thorough experimental investigations of the theoretical premises of multidimensional attitude change.

This article describes an experiment that tested six hypotheses fundamental to such theories.

\section{THEORY}

All multidimensional attitude change models rest on the assumption that the stimuli or concepts composing an attitude domain are multidimensional. They do not lie along a single line or unidimensional continuum. A number of studies already have confirmed this (cf. Marlier, 1976; Gillham \& Woelfel, 1977; Barnett, 1975; Cody, 1976; see also Romney et al., 1972).

Each multidimensional analysis, however, explicitly tests this premise. So, in this examination of the theoretical premises of such analyses, it becomes the first hypothesis:

$\mathrm{H}_{1}$ : Stimuli defining the domain of attitudes may comprise a multidimensional rather than unidimensional pattern.

In the relatively rare, extremely simple situations where the domain may prove unidimensional, the multidimensional analysis would reveal this by producing a unidimensional solution.

A second assumption underlying multidimensional attitude change models involves the changing positions of stimuli-or concepts-within a domain, relative to each other. Specifically, an attempt to change attitudes would result in a shift in the positions of any stimuli used in the attempt.

Unidimensional approaches, of course, limit such changes to the unidimensional continuum assumed to underlie the stimuli. Besides the magnitude of change, therefore, these analyses are only concerned with whether it proceeds in the intended direction or in the opposite-the well-known boomerang effect.

Multidimensional analyses, on the other hand, do not constrain the direction of change. So far this question has received little theoretical attention. But work by Woelfel and Saltiel (1974) and Woelfel $(1976,1978)$ provide the basis for a general hypothesis:

Stimuli associated with each other in the persuasion process will converge with each other in the multidimensional attitude domain.

This general hypothesis, in turn, becomes the basis for four specific hypotheses tested in this experiment. First, when a person receives a message saying "you should adopt position X," the person's self-concept-or the "me" in the experimentwould be expected to become more closely associated with the position. So the second hypothesis says:

$\mathrm{H}_{2}$ : The self should converge with the advocated position in the attitude domain.

The source of advocacy message also would be expected to become more closely identified with the position. The third hypothesis, therefore, states: 
$\mathrm{H}_{3}$ : The source(s) of a persuasive message and the position advocated by the source(s) converge in the attitude domain.

Extended to multiple sources, this becomes the fourth hypothesis:

$\mathrm{H}_{4}$ : When multiple sources advocate the same position, these converge on each other.

Since both the message sources and the self are expected to converge on the advocated position, the sources and the self would logically be expected to converge on each other. So the fifth hypothesis states:

$\mathrm{H}_{5}$ : The source(s) of a persuasive message and the self concept (me) of the recipient converge in the attitude domain.

Hypotheses 2-5 involve at least two different kinds of associations among stimuli. The first, existential association, involves stating or at least implying that the stimuli are the same or similar. The other hortatory association consists of stating or implying that the stimuli should be the same or similar.

Two sources, for example, may convey the message: "You should adopt position X." This implies that the sources are similar to each other and to position $\mathrm{X}$, making the association of the sources and the position existential. But the message also implies that the "you" - - r the self, from the receiver's viewpoint-should become more like the sources by adopting the position they advocate. "You" and position X, therefore, have a hortatory association. General existential associations, in which the stimuli are the same or similar, should be stronger than hortatory associations in which they should be the same or similar.

For this study, this difference is important because it would be expected to be reflected in the findings for Hypotheses 2-5. So the sixth hypothesis becomes:

$\mathrm{H}_{6}$ : Advocacy involving existential associations of stimuli should be more effective (i.e., produce a greater absolute magnitude of change) than that involving hortatory associations.

\section{METHOD}

The experiment devised to test these six hypotheses involved a four-wave longitudinal design. During the first wave, 46 students at the University of Akron were given a test booklet which described itself as an inquiry into the diffusion of an innovation. The innovation itself was referred to as the "cortical-thematic-pause" the first time, and then abbreviated thereafter as the CTP. No substantive definition of CTP whatsoever was provided to the subjects, so that the set of concepts, in terms of which subjects later defined it, could be specified completely within the experiment itself. Thus, the effects of prior attitudes toward the CTP were deliberately minimized. Subjects were told that little was known about the CTP, but that some evidence showed it was completely harmless, took only moments to perform, and did not interfere with other ongoing activity. Subjects were told that the purpose of the experiment was to determine how their perceptions of the CTP changed as it disseminated through the culture. They were also told that the experimenters had contacted researchers studying the CTP and would relate to them the results of those inquiries.

The subjects then completed a Galileo-type complete pair comparison instrument (Gillham \& Woelfel, 1977), which asked them to estimate the differences in meaning among 16 concepts:

1. Sleeping

2. Dreaming

3. Day Dreaming

4. Intense Concentration

5. Marijuana High

6. Good

7. Depression

8. Alcohol High

9. Relaxation

10. C.T.P.

11. Alpha Wave Meditation

12. Transcendental Meditation

13. Reliable 
14. Timothy Leary

15. Linus Pauling

16. $\mathrm{Me}$

Of these concepts, 10 (sleeping, dreaming, daydreaming, intense concentration, marijuana high, depression, alcohol high, relaxation, alpha wave, and transcendental meditation) represented a range of cognitive states which define the domain of meaning for the CTP in this study. Two concepts (Timothy Leary and Linus Pauling) represent ostensive sources of messages the subjects would receive later. These were the names of two prominent persons who, on the basis of their widely publicized interests, could, conceivably, be involved in research on a phenomenon like CTP.

These two persons, who were to serve as message sources in the experiment itself, were selected on the basis of a pretest among college students. The first, Linus Pauling, was a Nobel laureate who, the pretest showed, would be considered a relatively credible source. The other, Timothy Leary, was a well-known academician, serving a prison sentence at the time, who was rated as far less credible in the pretest.

Two additional concepts (good and reliable) represent attribute descriptors which may be used to describe both the cognitive states and the sources. The word "reliable" was inserted particularly to measure the perceived credibility of the source. The remaining two concepts included were " $m e$ " or the subjects' "self," representing the subjects' own positions, and CTP itself.

These 15 concepts, excluding "me," were not chosen as the domain because they bear any inherent relationship to the CTP. Rather, the CTP, as a fictitious concept, was left completely undefined. Whatever definition it acquired resulted from its association with these other stimuli. These concepts, therefore, constitute the only definition of the CTP made available to the respondents and establish the domain of meaning for the CTP by definition.

When formulated into the Galileo-type complete pair comparison instrument, these 16 total concepts yielded a total of 120 pairs. For each pair, respondents were asked to estimate the distance between the two concepts.
This ratio judgment of separation method (Danes \& Woelfel, 1975; Woelfel, 1974) requires a criterion pair, established by a statement of the form: "If $a$ and $b$ are $U$ units apart, how far apart are and ___?" In this case, the criterion pair consisted of "red" and "white," set at a criterion distance of 50 Galileos, a measure of social distance used in previous studies. Subsequent research (see Gordon \& DeLeo, 1975) has shown that a criterion pair that, as in this case, is not drawn from the stimuli domain is roughly equivalent to a widely separated pair within the domain. If we had chosen an interior criterion pair, the precision of the measurement would probably have been greater.

Subjects were told that the experiment sought to determine changes in their perceptions of CTP as information about it disseminated through the culture. They also were told that we had requested further information from researchers studying the phenomenon and would relay any responses to these inquiries.

Two days after initially completing the questionnaire, these students were given copies of a letter ostensibly from Linus Pauling and written on the letterhead of a research institute. In this letter, the source gave a seemingly erudite description of CTP and recommended that it be performed several times a day. The respondents then were asked to fill out the questionnaire a second time.

Five days after the second administration (class schedules required unequal time intervals), the students were given copies of a letter-on forged prison stationery-supposedly from Timothy Leary. It contained essentially the same information as Pauling's letter. Care was taken to make both letters similar in style and content, although the first was somewhat more technical in tone. Both were about the same length. The second letter was more sloppily typed. At this point, the students filled out the questionnaire a third time.

Two days later the questionnaire was administered a fourth time, without further experimental manipulations. The students were then debriefed. Mean administration time for those 16-concept Galileo-type instruments, including manipulations, was approximately 23 minutes. This is worth noting, since some researchers have mistakenly as- 
sumed that these instruments require long administration times and place a heavy burden on respondents. In our experience, differences in response time and respondent burden between conventional instrumentation and Galileo-type instrumentation are negligible in practice.

\section{ANALYSIS}

Data from all four administrations were entered into the Galileo Version 5 computer program at SUNY-Albany for analysis. (Results were also checked against Galileo Version 3.5 at Michigan State University Galileo Version 4 at the East-West Center and at SUNY-Albany, and all results except the rotation are identical on all versions. Versions 4.5 and 5 of the Galileo computer program contain an improved rotation option which produces a nearly perfect solution to the problem of comparing multidimensional Riemann spaces like those encountered here.) The maximum value option was set at 5,000 to eliminate missing data coded 99999, which reduced the sample size from a maximum possible 43 cases to an average cell size of 42.64 . Options selected included statistics, normal eigenvectors, rotated coordinates, distance moved summary table, row and column correlations. These provided the basis of the results presented below.

\section{RESULTS}

Although the reliability and precision of Galileo measurements have been well-documented (see Gillham \& Woelfel, 1977), nonetheless, it is appropriate to discuss their precision in the present context. Fortunately, the configuration of Galileo data lends itself well to unambiguous tests of precision/reliability. Of first interest is the precision/ reliability of the raw pair comparison measures which provide the basis for analysis. The 16 concepts used in the study yield $N(N-1) / 2$ or 120 pair comparisons per time over each of four time periods. Four of these concepts—-the CTP, Pauling, Leary, and the "me"- -were manipulated in the study, and thus 55 of the pair comparisons contain at least one manipulated concept. On the assumption that manipulation effects are negligible for the 65 unmanipulated pairwise distances, these distances may be taken as constants across the (brief) lifespan of the study. (If this assumption is false, all precision measures will be underestimates). Standard deviations across the four time periods for each of these 65 unmanipulated distances may therefore be used as estimators of the standard errors of measure. Each of these 65 pairwise distances was therefore averaged across the four time periods; the 65 standard errors were then calculated. Based on these data, the 65 appropriate coefficients of variation $(\mathrm{V}$ $\left.=100\left(\sigma_{\mathrm{X} 1} / X_{1}\right)\right)$ were then calculated. Each of these may be read directly and conveniently as a percent error of measure for each pair comparison. This is very convenient, since there is (approximately) a 68 percent probability that the true score lies within $\pm V \%$ of the measured value, and a $99 \%$ probability that the true score lies within $\pm 2 \mathrm{~V} \%$ of the measured value. These scores are presented in Table 1.

As Table 1 shows, these coefficients range from a low of 2.2 percent to a high of 35.8 percent. The average error of 9.23 percent should be considered excellent, given the highly complex nature of the attitude domain and the small sample size ${ }^{1}$ $(N=42.64)$.

The highest error ( 35.8 percent), moreover, was recorded by the first pair on the questionnaire-the first distance estimate ever done by the respondents. This indicates that, in future studies, several dummy pairs might precede the main questionnaire to give respondents experience with this type of instrument.

By comparison, a standard error of one on a five-point Likert-type scale corresponds to 20 percent error. Standard errors of two or morecorresponding to percent errors of 40 or greaterare commonplace in Likert-type measures at $N=40$.

These data provide very substantial evidence that the raw pair-comparison data yield highly precise and reliable mean scores. Evidence about the precision and stability of the overall configuration is given in Tables 2 and 3. Table 2 gives the correlations between corresponding dimensions of the configuration for adjacent datasets. Column correlations represent the cosines of the angles between the corresponding columns of adjacent datasets; 
TABLE 2

Pearson Correlations (Cosines) and Angles ( $\alpha$ ) Between Corresponding Columns (Dimensions) of Contiguous Measurement Periods

\begin{tabular}{ccccccc}
\hline Colum & \multicolumn{1}{c}{$\mathrm{T}_{1}-\mathrm{T}_{2}$} & \multicolumn{2}{c}{$\mathrm{T}_{2}-\mathrm{T}_{3}$} & \multicolumn{2}{c}{$\mathrm{T}_{3}-\mathrm{T}_{4}$} \\
& $\mathrm{r}$ & $\alpha$ & $\mathrm{r}$ & $\alpha$ & $\mathrm{r}$ & $\alpha$ \\
\hline 1 & .91 & 25 & .82 & 35 & .90 & 26 \\
2 & .96 & 17 & .88 & 29 & .96 & 16 \\
3 & .95 & 18 & .97 & 15 & .96 & 17 \\
4 & .85 & 32 & .87 & 30 & .95 & 17 \\
5 & .89 & 27 & .59 & 54 & .45 & 64 \\
6 & .34 & 70 & .63 & 51 & .69 & 47 \\
7 & .32 & 71 & .79 & 38 & .70 & 46 \\
8 & .55 & 57 & .76 & 41 & .68 & 47 \\
9 & .53 & 58 & .15 & 81 & .95 & 18 \\
10 & .65 & 49 & .59 & 54 & .47 & 62 \\
11 & .20 & 78 & -.05 & 93 & .40 & 67 \\
$12 *$ & $* *$ & $* *$ & -.19 & 101 & .76 & 40 \\
$13 *$ & -.07 & 94 & .06 & 87 & .36 & 69 \\
$14 *$ & .19 & 79 & .09 & 85 & .43 & 65 \\
$15 *$ & .58 & 54 & .44 & 64 & .51 & 59 \\
$16 *$ & .74 & 43 & .87 & 30 & .89 & 27 \\
& & & & & & \\
\hline
\end{tabular}

*Dimension is imaginary.

**Angle 18 Imaginary.

corresponding dimensions are imaginary. (For a sum of squares to be negative, the numbers squared must be imaginary, since $i^{2}=-1$.) These imaginary eigenvectors are clearly not the result of random measurement error, since they are quite stable over the four intervals, as their correlations in Table 2 show.

Some writers (Woelfel \& Danes, 1979; Woelfel, Barnett, \& Dinckelacker, 1978) have suggested that non-Euclideanisms are the result of cognitive imbalance or dissonance. These authors (1978) have proposed the ratio of the sum of the real eigenvalues to the sum of all eigenvalues as a measure of global departure from a Euclidean configuration. This statistic, which they call the Warp Factor, is indeed a measure of the degree to which the space or plane is warped away from its flat Euclidean counterpart. When the space is not warped at all, it will be Euclidean and there will be no negative eigenroots; thus, the Warp Factor will be 1.00 . As the space departs from Euclideanism, negative eigenroots will appear, and the Warp Factor will grow larger than 1.00 . In the present case, the warp factor de-
TABLE 3

Pearson Correlations (Cosines) and Angles ( $\alpha$ ) Between Corresponding Rows (Concepts) of Contiguous Measurement Periods

\begin{tabular}{|c|c|c|c|c|c|c|c|}
\hline Row & Concept & $T_{1}$ & & $\mathrm{~T}_{2}$ & $\begin{array}{r}-T_{3} \\
a\end{array}$ & $\mathrm{~T}_{3}$ & $T_{4}$ \\
\hline $\begin{array}{c}1 \\
2 \\
3 \\
4 \\
5 \\
6 \\
7 \\
8 \\
9 \\
10 \\
11 \\
12 \\
13 \\
14 \star \\
15 * \\
16 \star\end{array}$ & $\begin{array}{l}\text { Sleeping } \\
\text { Dreaming } \\
\text { Daydreaming } \\
\text { Intense Concern } \\
\text { Marljuana H1gh } \\
\text { Good } \\
\text { Depression } \\
\text { Alcohol H1gh } \\
\text { Relaxation } \\
\text { CTP } \\
\text { Alpha Wave Med. } \\
\text { T.M. } \\
\text { Reliable } \\
\text { T1mothy Leary } \\
\text { I1nus Pauling } \\
\text { Me }\end{array}$ & $\begin{array}{r}.90 \\
\star * \\
.99 \\
.97 \\
.97 \\
.82 \\
\star \star \\
\star \star \\
.98 \\
.00 \\
\star \star \\
1.00 \\
.95 \\
.67 \\
.49 \\
.70\end{array}$ & $\begin{array}{r}26 \\
* * \\
7 \\
15 \\
15 \\
35 \\
\star * \\
k * \\
10 \\
90 \\
* * \\
3 \\
17 \\
48 \\
61 \\
45\end{array}$ & $\begin{array}{l}.93 \\
.97 \\
.99 \\
.94 \\
.95 \\
.83 \\
.99 \\
\star \star \\
.86 \\
. .20 \\
.95 \\
.98 \\
.97 \\
.12 \\
.37 \\
.76\end{array}$ & $\begin{array}{r}21 \\
13 \\
8 \\
20 \\
19 \\
34 \\
8 \\
* \star \\
31 \\
102 \\
18 \\
10 \\
14 \\
83 \\
68 \\
40\end{array}$ & $\begin{array}{r}.97 \\
.96 \\
.98 \\
.94 \\
.98 \\
.95 \\
.98 \\
1.00 \\
.93 \\
.86 \\
.97 \\
.98 \\
.98 \\
-.01 \\
.55 \\
.90\end{array}$ & $\begin{array}{r}13 \\
16 \\
12 \\
19 \\
10 \\
17 \\
10 \\
0 \\
22 \\
31 \\
14 \\
9 \\
11 \\
93 \\
57 \\
26\end{array}$ \\
\hline
\end{tabular}

Manipulated concept.

**Angle is lmaginary.

creases monotonically over the course of the experiment, with values of $1.187,1.142,1.103$, and 1.087. This indicates that the space tends to become increasingly Euclidean as the experiment proceeds, which we interpret to mean that the space is viewed increasingly consistently by the sample. $\mathrm{H}_{1}$, therefore, is clearly supported by these data.

Figure 2 shows the plots of the first two dimensions of the configuration at each of the four measurement periods. Figure 2 is meant only to provide a rough visualization of the configuration and to show approximate changes in the configuration as a result of the manipulations.

Rotations and translations to least-squares-bestfit by means of the Galileo Version with the manipulated concepts $(10,14,15$, and 16) left free under the free concepts (FCONS) option. Both Figure 2 and Table 6 show fairly clearly that the manipulated concepts exhibit substantially more motion than concepts not manipulated. Moreover, even though Figure 2 is only a partial representation of the space, it is clear enough to show that what motions do take place are very far from being constrained to a unidimensional continuum. Both Table 6 and Figure 2 show also that the manipulated concepts continue to exhibit motion across the last measurement interval in spite of the fact that no 
TABLE 4

Mean Distances, Standard Deviations, and Sample Sizes Among Six Pairs of Concepts at Four Measurements $\left(\delta_{\mathrm{x}}\right.$ in parentheses)

\begin{tabular}{lllll}
\hline \multirow{2}{*}{ Concept Pair } & \multicolumn{4}{c}{ time period } \\
& $\mathrm{T}_{1}$ & $\mathrm{~T}_{2}$ & $\mathrm{~T}_{3}$ & $\mathrm{~T}_{4}$ \\
\hline
\end{tabular}

$\begin{array}{lcccc}\text { Pauling - Reliable } & 66.79 & 61.60 & 64.67 & 61.38 \\ & (7.822) & (10.36) & (11.658) & (12.097) \\ & 42 & 42 & 43 & 42 \\ \text { Leary - Reliable } & 78.00 & 74.23 & 74.56 & 73.56 \\ & (8.804) & (13.403) & (14.110) & (14.887) \\ & 43 & 43 & 43 & 43 \\ \text { CTP - Me } & 77.60 & 70.60 & 78.84 & 73.12 \\ & (18.006) & (11.095) & (14.627) & (14.892) \\ \text { CTP - Paulling } & 42 & 42 & 43 & 42 \\ & 90.19 & 53.929 & 53.63 & 57.05 \\ & (9.661) & (10.592) & (9.837) & (10.361) \\ \text { CTP - Leary } & 42 & 42 & 43 & 42 \\ & 91.88 & 81.548 & 51.81 & 55.86 \\ & (4.994) & (15.107) & (9.486) & (10.056) \\ \text { Pauling - Leary } & 42 & 42 & 42 & 42 \\ & 54.33 & 66.33 & 48.28 & 52.70 \\ & (7.132) & (10.231)(11.535) & (9.464) \\ \text { Pauling - Me } & 42 & 42 & 43 & 43 \\ & 80.36 & 99.52 & 81.16 & 79.76 \\ & (7.13) & (10.23) & (11.54) & (9.46) \\ \text { Leary - Me } & 42 & 42 & 43 & 42 \\ & 83.35 & 101.98 & 83.72 & 82.56 \\ & (7.74) & (11.70) & (12.21) & (9.93) \\ & 43 & 43 & 43 & 43 \\ & & & & \end{array}$

further treatments were applied, but Figure 2 makes it evident that this postmanipulative motion is indeed motion toward the initial state of the configuration. It does not represent the concepts continuing in their trajectories, but rather shows them tending to move back toward their original positions after the treatments are discontinued. Figure 3 makes this motion even more evident, since it depicts only the manipulated concepts, with each time period overlaid on the preceding one. Squares represent the time 1 locations of the concepts, while triangles represent time 2 , circles time 3 , and stars time 4.

Table 4 contains information parallel to these two figures and specifically pertinent to Hypotheses 2-5. The first, $\mathrm{H}_{2}$, predicts that the self-concept ("me") should converge with the advocated position. The distance between CTP and "me" (row 3 in Table 4) tests this movement. Between $t_{1}$ and $t_{2}$, the mean distance between CTP and "me" drops seven units with the delivery of the credible source (Pauling) message advocating daily practice of the CTP. In Figure 2, this same change is represented by a decrease in distance between concept 16
TABLE 5

Eigenvalues at Four Measurements

\begin{tabular}{crrrr} 
E1genvalue & \multicolumn{1}{c}{$T_{1}$} & $T_{2}$ & \multicolumn{1}{c}{$T_{3}$} & \multicolumn{1}{c}{$T_{4}$} \\
\hline 1 & 13634 & 9681 & 8317 & 7755 \\
2 & 7930 & 7156 & 7483 & 7618 \\
3 & 5917 & 5074 & 5182 & 5434 \\
4 & 4689 & 3678 & 4339 & 3820 \\
5 & 2706 & 3073 & 2333 & 2868 \\
6 & 2308 & 2684 & 1876 & 1493 \\
7 & 2117 & 1394 & 1692 & 1382 \\
8 & 1157 & 930 & 1162 & 1226 \\
9 & 915 & 651 & 944 & 827 \\
10 & 653 & 484 & 520 & 698 \\
11 & 134 & 398 & 294 & 459 \\
12 & 000 & -10 & 35 & 167 \\
13 & -185 & -263 & -00 & 00 \\
14 & -1658 & -557 & -29 & -327 \\
15 & -1920 & -920 & -687 & -603 \\
16 & $-2867-2618$ & -2470 & -1762 \\
\hline
\end{tabular}

("me") and concept 10 (CTP) from $t_{1}$ to $t_{2}$. In Figure 3, the same process is represented as the motion of concept 16 from the $t_{1}$ position, designated by a square with a " 16 "' in it, to its $t_{2}$ position, represented by a triangle, and, simultaneously, by the smaller motion of CTP from its $t_{1}$ position, represented by a square with a " 10 " in it, to its $t_{2}$ position, represented by a triangle. All the distances in Figure 3 correspond exactly to those in Figure 2, and, in fact, Figure 3 may be overlaid on Figure 2 exactly.

Between $t_{2}$ and $t_{3}$, however, when the noncredible source delivers essentially the same message, the two concepts diverge dramatically. At $t_{4}$, the posttest measurement, the distance again drops, this time to a point about midway between the $t_{2}$ and $t_{3}$ measurements.

The movements between $t_{1}$ and $t_{2}$ clearly support $\mathrm{H}_{2}$ : the concepts CTP and " $m e$ " do converge after association with each other in the persuasion process. This change is significant with a BehrensFisher $D=2.4(p<.01)$. But the $\mathrm{t}_{2}-\mathrm{t}_{3}$ movements reflect the classic "boomerang" effect. Although Leary, like Pauling, advocated daily practice of CTP, CTP and "me" move apart, a change that is significant at better than the .05 level. This qualifies the findings on $\mathrm{H}_{2}$ by indicating that the credibility of the source can affect the convergence of associated concepts through not only a smaller impact 
than a more credible source, but also, in this case, a negative impact. The $t_{3}-t_{4}$ difference, also significant at $p<.05$, shows the decay of the treatment's effect with time.

Rows 4 and 5 of Table 4 contain data on $\mathrm{H}_{3}$ : the source(s) of a persuasive message and the positions they advocate will converge in the attitude domain. For Pauling, this is confirmed by the dramatic drop in the distance between CTP and Pauling in the $t_{1}-t_{2}$ period. As expected from the timing of the two messages, the CTP-Leary distance shows its largest decrease in the $t_{2}-t_{3}$ period. Both movements are very strong and highly significant—well beyond the .001 level.

Again, the effects of the treatment decay with time, although, in Pauling's case, this decay does not show up until the $t_{3}-t_{4}$ interval instead of the $t_{2}-t_{3}$ interval, as might be expected. But, for both Pauling and Leary, the differences in the $t_{3}-t_{4}$ distances are significant at $p<.05$.

Data in row 6 of Table 4 support $\mathrm{H}_{4}$ : sources that advocate the same position will converge with each other. In this case, the sources intitially diverge $\left(t_{1}-t_{2}\right)$ as Pauling endorses CTP, while Leary has yet to be heard from. Once Leary has revealed a position similar to Pauling's, the two sources converge sharply $\left(t_{2}-t_{3}\right)$. Once more, the $t_{4}$ measurement shows treatment decay with time with a significance level of $p<.05$.

As illustrated by the last two rows of Table 4, findings are more comlex for $\mathrm{H}_{5}$ : the source(s) of an advocacy message and the self-concept of the recipient will converge in the attitude domain. Although Pauling delivers such an advocacy message between $t_{1}$ and $t_{2}$, Pauling and "me" diverge rather than converge during this interval. More surprisingly, Leary and "me" also diverge, even though Leary has yet to take an advocacy position. Both divergences are highly significant at the .001 level.

In this instance, the Pauling- "me"'divergence may be explained by the nature of the phenomenon in the advocacy message. The respondents had heard of CTP only once before-at the first administration of the questionnaire. So, at this stage, the message from Pauling, citing his extensive investigations into CTP, quite likely may have lead the
TABLE 6

Distances Moved Across Four Measurements

\begin{tabular}{|c|c|c|c|c|}
\hline \multicolumn{2}{|r|}{ Concept } & \multicolumn{3}{|c|}{ Diarance Yoved } \\
\hline & & & & \\
\hline 1 & Sleep1ng & 14.56 & 11.98 & 7.92 \\
\hline 2 & Dreaming & $6.951 k \hbar$ & 5.59 & 9.06 \\
\hline 3 & Daydreaming & 4.18 & 4.66 & 7.49 \\
\hline 4 & Intense concentration & 13.30 & 15.22 & 15.65 \\
\hline 5 & Marijuane high & 12.69 & 16.35 & 4.92 \\
\hline 6 & Good & 19.59 & 20.19 & 11.99 \\
\hline 7 & Depreasion & 14.321 & 8.071 & 9.30 \\
\hline 8 & Alcohol high & 3.441 & 13.961 & 6.431 \\
\hline 9 & Relaxation & 6.13 & 16.20 & 3.68 \\
\hline 10 & CTP & $59.60 *$ & $72.37^{\star}$ & 28.15 \\
\hline 11 & Alpha Wave Med. & 11.641 & 12.71 & 8.41 \\
\hline 12 & Transcendental & 3.741 & 11.32 & 2.721 \\
\hline 13 & Reliable & 15.92 & 11.86 & 9.69 \\
\hline 14 & Timothy Leary & 61.81 & $82.84 *$ & 87.32 \\
\hline 15 & Linus Pauling & $78.12 *$ & 70.04 & 57.59 \\
\hline 16 & Me & $45.04 *$ & $34.47 *$ & 19.67 \\
\hline
\end{tabular}

FConcept manipulated prior to this interval.

* Lowercase 1 indicates net motion is imaginan, which means the absolute magnitude of the motion of the concept in the imaginary part of the Rlemann space exceeded that in the real part.

respondents to envision themselves even less similar to Pauling than before.

But the concurrent divergence of Leary and "me" is more enigmatic. Possibly, the inclusion of both Pauling and Leary on the test instrument led respondents, in some way, to associate them with each other, even though the sources themselves diverge in this interval $\left(\mathrm{H}_{4}\right)$.

Such an association also may help explain the equally puzzling changes in the $t_{2}-t_{3}$ period. As expected, Leary, who delivers his advocacy message at this point, converges with "me." But, concurrently, Pauling also converges with "me," even though no further advocacy on his part had been introduced. Again, both changes are significant at $p<.05$. So, at best, these results only partially support $\mathrm{H}_{5}$.

Finally, the six pairs of manipulated concepts (rows 3-8 in Table 2) provide a test of $\mathrm{H}_{8}$ : advocacy involving existential associations of stimuli should be more effective than that involving hortatory associations. Three of these pairs, Pauling--CTP, Leary-CTP, and Pauling-Leary, constitute unequivocal instances of existential associations. As anticipated, the pairwise distances decrease with the manipulations. This decrease, in fact, averages 28.02 units.

The CTP-"me" distances reflect the two instances of hortatory associations in this study: the letters from Pauling and Leary advocating daily 
FIGURE 2

First Principal Plane of the Neighborhood of the CTP at Four Points in Time. Top left (squares) represents configuration prior to manipulations. Top right (triangles) represents configuration immediately after Pauling's advocacy of the CTP. Bottom left represent configuration after Leary's advocacy (circles), and bottom right (stars) represents the configuration two days later than the third figure, with no additional manipulations. Note particularly the convergences of Pauling, Leary, and the CTP after the manipulations, and their subsequent divergences later. Concepts are numbered the same as in Table 3.

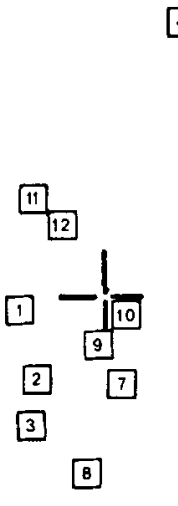

5
(12)

(11)

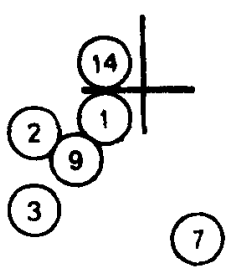

(5)

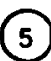

\section{7)}

14

\section{(4)}

(13)

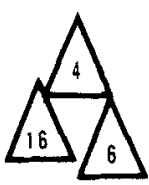

16
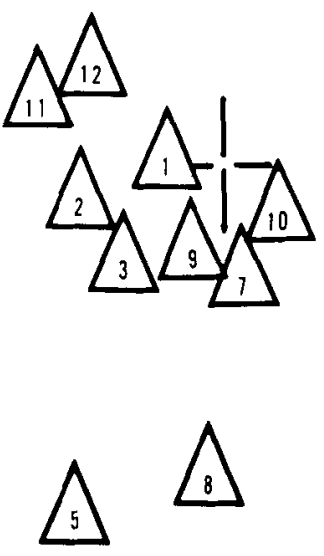

$\Delta$

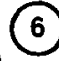

(15)

(10)
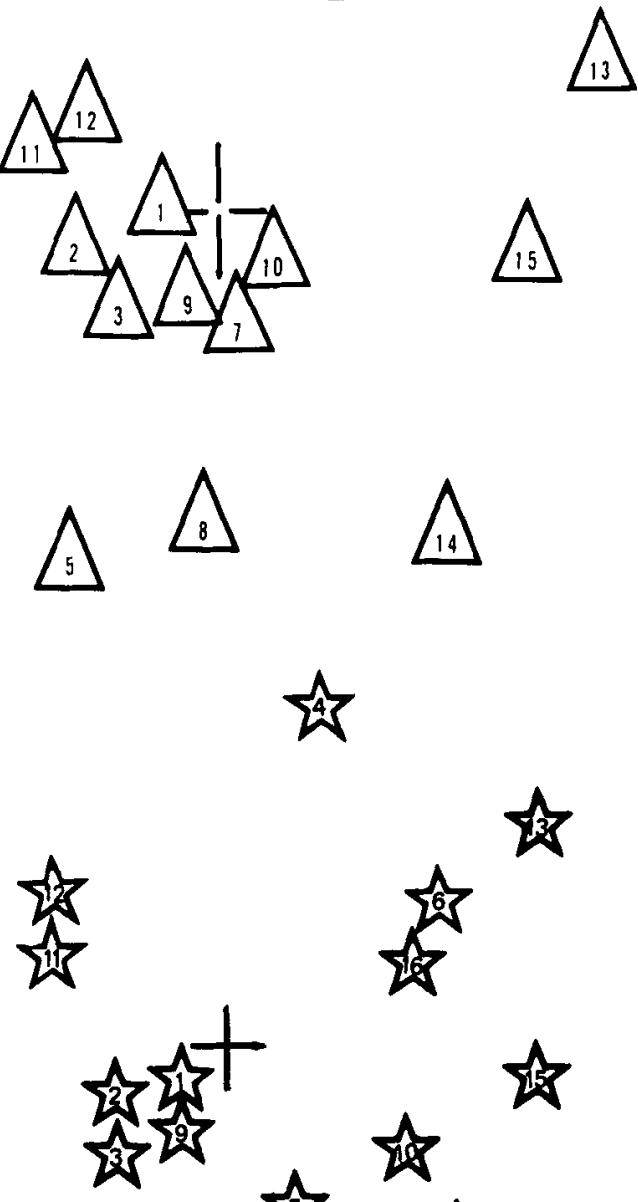

practice of CTP. As noted earlier, Pauling's advocacy reduces the CTP_- "me" distance by 7 units, while Leary's increases it by 8.24 units (the boomerang effect). But even considering just the absolute values of these movements yields an average change of only 7.62 units, significantly less
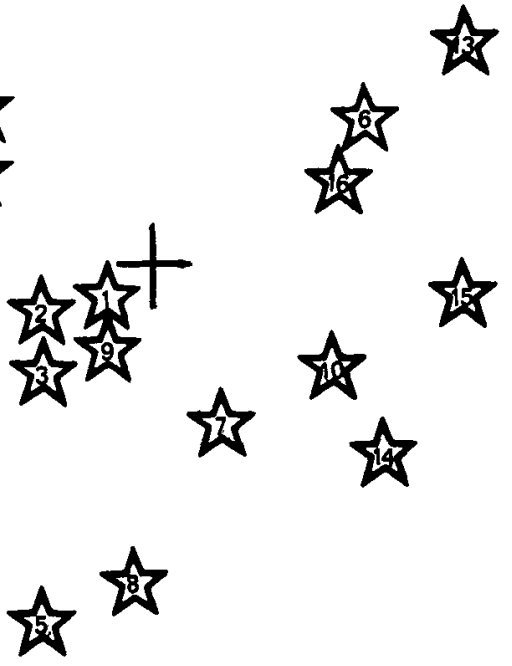


\section{FIGURE 3}

Trajectories of Only the Manipulated Concepts over the Four Measurement Periods. Squares represent time 1, triangles time 2, circles time 3 , and stars time 4. Arrowheads indicate the direction of time.

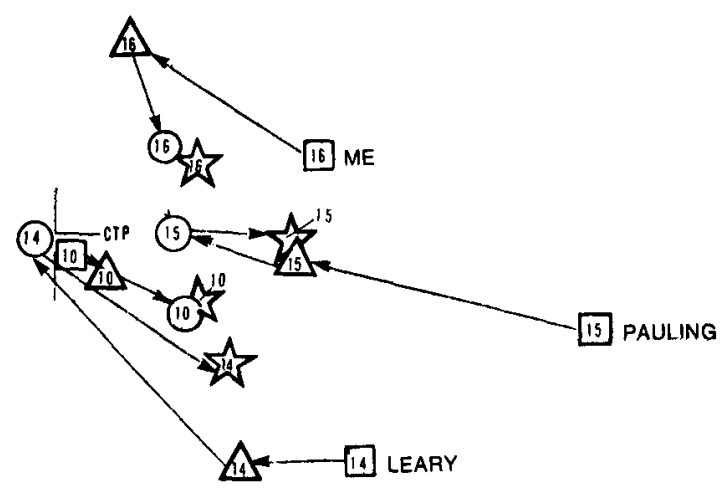

$(p<.001)$ than the 28.02 -unit average change recorded by the three instances of existential association. This, therefore, supports the hypothesis that existential associations of stimuli are more effective than hortatory associations in the persuasion process.

\section{DISCUSSION}

In summary, the findings unequivocally support four of the six hypotheses. The solution is multidimensional $\left(\mathrm{H}_{1}\right)$. The source(s) of a persuasive message converge on the position they advocate $\left(\mathrm{H}_{3}\right)$. Multiple sources converge on each other $\left(\mathrm{H}_{4}\right)$. Existential association of stimuli is more effective than hortatory associations $\left(\mathrm{H}_{6}\right)$.

To some extent, the findings also support the hypothesis that, in the persuasion process, the self should converge with the advocated position $\left(\mathrm{H}_{2}\right)$. In this case, the effort by a credible source brought the predicted convergence, while a similar effort by a noncredible source produced a boomerang effect.

In part, these results, likewise, support the hypothesis that the source(s) of a persuasive message will converge with the self-concept " $m e$ " $\left(\mathrm{H}_{5}\right)$. Although this convergence appears at $t_{3}$, it does not follow the pattern of the manipulations and is not completely explainable by current theory.
The ambiguities in these findings point to a number of issues for further research. The first involves the nature and the degree of the effect of a source's credibility in the persuasion process. Another evolves around the interaction of sources, especially in the recipient's perceptions. A persuasion attempt that involves multiple sources, for example, could be self-defeating if some sources cancel out the effects of others.

An equally important issue consists of the effects of time on persuasion efforts. This study detected a number of instances of the decay of the manipulation effect with time. Other researchers have noted another interesting phenomenon, the increase of the manipulation effect with time (Hovland, Janis, \& Kelley, 1953, pp. 280, 288).

Because of their versatility, multidimensional techniques are especially well suited for probing these and other questions on attitude change.

As interesting as these substantive results may be, the implications of these multidimensional procedures are at least equally important both theoretically and methodologically. On the theoretical level, the representation of the field of attitude change domains as multidimensional spatial arrays provides a geometric realization which is a distinct aid to theoretical speculation. Insofar as the success of efforts to map cognitive process onto multidimensional Riemann spaces continues in future efforts, insights gained from disciplines as seemingly removed from human activities as cosmology, high energy physics, and the physics of fluids and elastic solids may be applied fruitfully to the study of cognitive and cultural change. Notions of balance, for example, are clarified by understanding the extent to which inconsistencies in judgments lead to non-Euclidean structure in these domains, and furthermore provide precise and geometric quantification of what has heretofore been a highly qualitative study.

When concepts or ideas are represented as position vectors in a space, it is apparent visually that their meanings may be expected to average when used together, since the vector obtained by averaging the coordinates of any pair of vectors will bisect the line segment connecting those concepts. This is tantamount to saying that the meaning of a pair of 
words lies somewhere between those words. Similarly, the average of $n$ vectors yields a resultant vector whose end point lies at the exact center of those $n$ concepts, a concept which has intuitive appeal as the aggregate meaning of those $n$ concepts.

From a methodological viewpoint as well, these methods offer new possibilities to the attitude researcher. This study and others have shown clearly that it is possible to use ratio-scaled multidimensional methods within the context of traditional research, and that the precision of measure resulting generally exceeds typical practice by an order of magnitude. What may not be as clear from the present study is the ease and convenience with which this may be accomplished. Particularly with Galileo-type procedures, methods have been so extensively standardized and software has been so significantly automated that it is easily possible to execute a study like the present study in less time at less cost of time and resources than has been possible with more traditional methods. So much progress has been made, in fact, that even those familiar with these procedures from only a few years ago may be surprised by the simplicity and flexibility of modern multidimensional scaling technology.

Since multidimensional procedures are capable of reproducing any of the efforts of more traditional methods, and since they add additional information and theoretical power to such analyses, they deserve serious consideration as a generalized tool for the investigation of cognitive and cultural processes of any type. Moreover, since they are now so convenient and inexpensive to use, strong justifications will be needed from investigators who choose to continue to use the older, less precise, and informative investigative tools in these areas.

\section{NOTES}

We are grateful to Edward L. Fink and Katrina W. Simmons for helpful comments and technical assistance, and to Darlene Napady Gillham for editorial and stylistic assistance.

1. Three cases were deleted because insufficient subject identification information provided by respondents made it difficult to establish the time sequence in which the questionnaires were completed.

\section{REFERENCES}

ABELSON, R.P., \& MILLER, J.C. Negative persuasion via personal insult Journal of Experimental Social Psychology, 1964, 3, 321-333.

ARONSON, E., TURNER, J., \& CARLESMITH, J.M. Communicator credibility and communication discrepancy as determinants of opinion change. Journal of Abnormal and Social Psychology, 1963, 67, 31-36.

BARNETT, G.A. A paradigm for the measurement of meaning. Unpublished doctoral dissertation, Department of Communication, Michigan State University, 1975.

BARNETT, G., \& WOELFEL, J. On the dimensionality of psychological processes. Quality and quantity, forthcoming, 1979.

BERGIN, A.E. The effect of dissonant persuasive communications upon changes in a self-referring attitude. Journal of Personality, 1962, 30, 423-438.

BERLO, D., LEMERT, J., \& MERTZ, R. Dimensions for evaluating the acceptability of message sources. Public Opinion Quarterly, 1969, 33, 563-576.

BERSCHEID, E. Opinion change and communicatorcommunicatee similarity and dissimilarity. Journal of Personality and Social Psychology, 1966, 4, 670-680.

BOCHNER, S., \& INSKO, C. Communicator discrepancy and opinion change. Journal of Personality and Social Psychology, 1966, 4, 6, 614-621.

CODY, M.J. An application of the multiple-attribute measurement model: Measurement and manipulation of source credibility. Unpublished master's thesis, Department of Communication, Michigan State University, 1976.

DANES, J., \& WOELFEL, J. An alternative to the "traditional" scaling paradigm in mass communication research: Multidimensional reduction of ratio judgements of separation. Paper presented to the International Communication Association Annual Meeting, Chicago, Illinois, April 1975.

FISHER, S., \& LUBIN, A. Distance as a determinant of influence in a two-person interaction situation. Journal of Abnormal and Social Psychology, 1958, 56, 230-238.

FREEDMAN, J. Involvement, discrepancy, and change. Journal of Abnormal and Social Psychology, 1964, 69, 290-295.

GILLHAM, J., \& WOELFEL, J. The Galileo system of measurement: Preliminary evidence for precision, stability, and equivalence to traditional measures. Human Communication Research, 1977, 3, 222-234.

GOLDBERG, S. Three situational determinants of conformity to social norms. Journal of Abnormal and Social Psychology, $1954,49,325-329$.

GORDON, T.F. Subject abilities to use metric MDS: Effects of varying the criterion pair. Paper presented to the International Communication Association, Portland, Oregon, April 1976.

GORDON, T.F., \& DELEO, H.C. Structural variation in "Galileo" space: Effects of varying the criterion pair in metric multidimensional scaling. Unpublished manuscript, Temple University, Philadelphia, 1975.

HELSON, H., BLAKE, R., \& MOUTON, J. An experimental investigation of the effectiveness of the "Big Lie" 'is shifting attitudes. Journal of Social Psychology, 1958, 48, 51-60. 
HOVLAND, C., HARVEY, O., \& SHERIF, M. Assimilation and contrast effects in reactions to communication and attitude change. Journal of Abnormal and Social Psychology, 1957, 55, 244-252.

HOVLAND, C.I., JANIS, I.L., \& KELLEY, H.H. Communication and persuasion. New Haven: Yale University Press, 1953

HOVLAND, C.I., LUMSDAINE, A.A., \& SHEFFIELD, F.D. Experiments in mass communication: Studies in social psychology in World War II, vol. III. Princeton, N.J.: Princeton University Press, 1949.

HOVLAND, C., \& PRITZKER, H. Extent of opinion change as a function of amount of change advocated. Journal of $A b$ normal and Social Psychology, 1957, 25, 393-411.

HOVLAND, C.I., \& WEISS, W. Transmission of information concerning concepts through positive and negative instances. Journal of Experimental Psychology, 1953, 45, 175-182.

INSKO, C. Theories of attitude change. New York: AppletonCentury-Crofts, 1967.

INSKO, C., MURASHIMA, F., \& SAYADAIAN, M. Communicator discrepancy, stimulus ambiguity and influence. Journal of Personality, 1966, 34, 262-274.

KELLEY,H.H. , \& VOLKHART, E.H. The resistance to change of group-anchored attitudes. American Sociological Review, $1952,17,453-465$.

MANN, L. The effects of emotional role playing on smoking attitudes and habits. Unpublished doctoral dissertation, Yale University, 1965.

MARLIER, J.T. A metric multidimensional examination of socialjudgement predictions of assimilation, contrast, and attitude change. Unpublished doctoral dissertation, Michigan State University, 1976.

McCROSKEY, J.C. Scales for the measurement of ethos. Speech Monographs, 1966, 33, 65-72.

McQUIRE, W.J. The nature of attitudes and attitude change. In G. Lindzey and E, Aronson (Eds.), Handbook of social psychology, III. Reading, Mass.: Addison Wesley, 1969.

OSGOOD, C.E., SUCI, G.J., \& TANNENBAUM, P.H. The measurement of meaning. Urbana, Illinois: University of Illinois Press, 1957.

OSGOOD, C., \& TANNENBAUM, P. The principle of congruity in the prediction of attitude change. Psychological Review, 1955, 62, 42-55.

ROLOFF, M.E. An aplication of linear force aggregation theory to the relationship between the amount of change advocated in a message and the amount of attitue change obtained. Unpublished masters thesis, Michigan State University, 1974.

ROMNEY, A.K., SHEPARD, R.N., \& NERLOVE, S.B. (Eds.).Multidimensional scaling: Theory and applications in the behavioral sciences, vols. I, II. New York: Seminar Press, 1972.

ROSENBAUM, M., \& FRANC, D. Opinion change as a function of external commitment and amount of discrepancy from the opinion of another. Journal of Abnormal and Social Psychology, 1960, 61, 15-20.

SEROTA, K.B.Metric multidimensional scaling and communi- cation: Theory and implementation. Unpublished masters thesis. East Lansing: Michigan State University, 1974.

SEROTA, K., CODY, M., BARNETT, G., \& TAYLOR, J. Precise procedures for optimizing campaign communication. Paper presented at meeting of the International Communication Association, political communication division, "Top Three Paper," Berlin, Germany, June 1977.

SHEPARD, R.N. A toxonomy of some principal types of data and of multidimensional methods for their analysis. In A.K. Romney, R.N. Shepard, and S.B. Nerlove (Eds.), Multidimensional scaling: Theory and applications in the behavioral sciences, vol. I. New York: Seminar Press, 1972.

TATSUOKA, M. Multivariate analysis. New York: Wiley, 1971.

TUDDENHAM, R. The influence of distorted group norm upon individual judgement. Journal of Psychology, 1958, 46, 227-241.

WAKSHLAG,J., \& EDISON, N. A model for the validation of the source credibility construct. Paper presented at the Speech Communication Association Annual Meeting, December 1975.

WOELFEL, J. Metric measurement of cultural processes. Paper presented at the annual meeting of the Speech Communication Association, Chicago, 1974.

WOELFEL, J., BARNETT, G., \& DIN KELACKER,J. Metric multidimensional scaling in Riemann space. Paper presented to the Psychometric Society, Hamilton, Ontario, August 1978.

WOELFEL, J., \& DANES, J. New techniques for the multidimensionai analysis of communication and conception. In P. Monge and J. Cappella (Eds.), Multivariate analysis in communication research. Academic Press, 1979, fortheoming.

WOELFEL, J., \& HERNANDEZ, D. Media and interpersonal influence on attitude formation and change. Unpublished manuscript (mimeo), University of Illinois, 1970.

WOELFEL, J., SALTIEL, J., McPHEE, R., DANES, J., CODY, M., SEROTA, K., \& BARNETT, G. Orthogonal rotation to theoretical criteria: Comparison of multidimensional spaces. Paper presented at the annual meeting of the Mathematical Psychology Association, Purdue, Indiana, 1975.

WOELFEL, J., \& SALTIEL, J. Cognitive processes as motions in a multidimensional space. In Fred L. Casimir (Ed.), International and intercultural communication. University Press, 1979.

WOELFEL, J. Foundations of cognitive theory. In D.P. Cushman (Ed.), The message-attitude-behavior relationship. Academic Press, 1979, forthcoming.

WOELFEL, J., HOLMES, R., CODY, M., \& FINK, E. A mathematical procedure for optimizing political campaign strategy. Paper presented at International Communication Association annual meeting, Portland, Oregon, April 1976.

ZIMBARDO, P. Involvement and communication discrepancy as determinants of opinion conformity. Journal of Abnormal and Social Psychology, 1960, 60,86-94. 